Research Article

\title{
Buckling Behavior of Metallic Cylindrical Shell Structures Strengthened with CFRP Composite
}

\author{
Z. Draidi, ${ }^{1}$ T. T. Bui $\mathbb{D}^{2},{ }^{2}$ A. Limam $\mathbb{D}^{1},{ }^{1}$ H. V. Tran, ${ }^{2}$ and A. Bennani ${ }^{3}$ \\ ${ }^{1}$ University of Lyon, Lyon, France \\ ${ }^{2}$ INSA Lyon, GEOMAS, University of Lyon, Lyon, France \\ ${ }^{3}$ Institut inPACT, HEPIA Geneva, University of Applied Sciences Western Switzerland, Geneva, Switzerland \\ Correspondence should be addressed to T. T. Bui; tan-trung.bui@insa-lyon.fr and A. Limam; ali.limam@insa-lyon.fr
}

Received 30 March 2018; Revised 9 July 2018; Accepted 18 July 2018; Published 7 August 2018

Academic Editor: Michael Yam

Copyright () 2018 Z. Draidi et al. This is an open access article distributed under the Creative Commons Attribution License, which permits unrestricted use, distribution, and reproduction in any medium, provided the original work is properly cited.

The objective of this study is to evaluate the effect of a CFRP composite layer on the buckling behavior of metallic cylindrical shells. To enhance the bearing capacity of steel shells, classical solutions consider internal or external metallic stiffeners (stringers and/or rings) welded or riveted to the shell. Here, an external skin of composite material which wraps the whole metallic skin of the shell is studied. To be valid for metallic shells structures (storage tanks like silos) as well as for metal pipes (gas or oil pipeline), the procedure for setting up and implementing the composite must be simple. The recommended solution is therefore tested through experimental tests to find their limits and the configuration of optimal behavior. A consistent enhancement of bearing capacity is observed. This experimental base serves also to consolidate a numerical model which corroborates the experimental results. The good correlation between experimental and numerical results is confirmed for the whole loading process, for unstiffened and stiffened shells. For metallic unstiffened shell, an adequacy between experiment and simulation is noticed in the mainly membrane precritical behavior, during the buckling initiation characterized by the boundary layer problem corresponding to axisymmetric wavelength appearance near boundaries and in the postcritical domain associated to localization of the buckling mode at one extremity of the shell. For stiffened configuration, the enhancement of the bearing capacity of the shell is correctly gauged; this confirms the possibility to use finite element simulation for the design.

\section{Introduction}

Metallic shells structures are particularly sensitive to buckling or geometric instability. The design, based on the initial geometry, takes into account possible initial geometrical imperfections through knockdown factors. However, this initial configuration can suddenly or gradually evolve over time conducting to a no conservatism of the initial design. During the functioning, new shape defects can appear induced by accidental overloads or creep; also local corrosion due to severe environmental attacks can affect the material conducting to a decrease of the shell thickness. This can lead to diminution of the structure's lifetime. Furthermore, sometimes, due to the evolution of design rules that impose higher safety margins, for example, a new seismic design requirement by Eurocode 8 [1], strengthening of the structure should be considered. It is now of a fairly common practice to repair structures as it is nonexpensive and nonobstructive upgrading procedure. One of the common techniques to repair and strengthen steel shells is welds, rings, stringers, or local steel plate reinforcement. For example, Chen et al. [2] have proposed strengthening shells against elephant foot buckling using a small stiffener ring and discussed the size and position of this stiffener. More recent studies, Draidi [3], Bathika et al. [4], and Morteza and Hossein [5], explored a new concept of strengthening shells with composite material wrapped to the metallic skin. Composite materials, due to their high strength, high stiffness, resistance to corrosion, and low weight, can be of great interest in civil engineering structures. Their use is particularly interesting, especially in order to increase substantially the structural performance from the mechanical point of view, and also because of the ease of implementation which permits stealth construction. The optimization possibility, according to direction's 
reinforcement choice, and the multifunctional characteristics (strength, anticorrosion, and tightness) are particularly appreciated for civil engineering structures. Many studies have shown the relevance of FRP (fiber reinforced plastic) materials for the reinforcement of concrete structures [6-9] or masonry walls [10]. However, the use of CFRP in the repair and reinforcement of steel or concrete shells (see the contribution of Louhi et al. [11]) is a new concept still limited in literature review that has the potential to improve the way shells are repaired. The idea is to extend and consolidate this strengthening technique applied for the structures of metal shells against buckling. Few studies indeed consider the shells case but the reinforcement discussed is very localized, as patch to inhibit fatigue crack appearance or propagation [12], or to shade off localized defect and stop their effects $[13,14]$. To our knowledge, there has not yet been any quantitative study on the buckling behavior of metal shells strengthened with CFRP composite, based on both experimental and numerical approaches. In our study, buckling of thick metallic cylindrical shells structures submitted to uniform axial compression is experimentally and numerically investigated for the unstrengthened and CFRPstrengthened configurations. In the case of the reinforced configurations, different strengthened ratios with one to four layers of CFRP are considered. The results show that the load bearing capacity can be enhanced more than $40 \%$.

\section{Characterization of Composite Material}

The composite is a textile of carbon fibers oriented at $90^{\circ}$ in accordance with ISO 7211 standard; $70 \%$ of the fibers are in the warp direction, and $30 \%$ in the weft direction. For the composite carbon reinforced polymer layer, an epoxy resin with two EPONAL 380 components, serves as a matrix. The CFRP is a dry strip applied on a wet resin layer; setting up is manual (Figures 1 and 2) and requires no special surface treatment, apart from a degreasing process using a swab soaked in methylene. The application was executed with expert workmanship, following the recommended application procedure which underlines to use $40 \%$ resin for $60 \%$ strip. But this volume law strongly depends on composite application conditions. Although the CFRP bonding protocol is well defined, it is clear that the resin volume will be very different from one applicator to another, and also, the adhesion between CFRP layers themselves, or steel/composite adhesion, will be different for a shell to another.

For composite material characterization, specimens consisting of 1 to 4 composite layers are cut from laminated plates made under the same thermal and hydric conditions as the composite using for the shells reinforcement. The specimen geometry is defined according to the European standard NF EN 527-4.1997.

Two campaigns of classic uniaxial tests were conducted (six tests per configuration: the warp or weft direction and per loading mode: tension or compression). These tests allowed us to confirm the orthotropic elastic character of the composite until the ultimate failure. For certain tensile tests, localized failures of fibers are observed before reaching the ultimate stress. In the optimum direction of composite, an average ultimate stress of $1400 \mathrm{MPa}$ is obtained, and local fibers failures appear systematically beyond a stress of about $800 \mathrm{MPa}$. Variations between tensile tests are low, below $10 \%$ for the elastic modulus in the warp and weft direction. For ultimate stress, the values are widely scattered in the case of samples having only one CFRP layer. This dispersion is less in the case of the specimens having more than two layers of CFRP. Table 1 summarizes the average mechanical characteristics obtained in tensile tests.

The compression behavior is very different from that in tension. The compression tests are very difficult to achieve because of the buckling phenomenon and microbuckling or delamination. For one layer under the compression, the modulus is almost that of the resin. However, when the layers number increases, the compression modulus increases which means that the fibers have a significant contribution. In Table 1, the results in the case of specimens comprising three layers are presented.

\section{Experimental Study}

3.1. Specimens Geometry. The mild steel cylindrical shells' geometrical parameters are defined in Figure 3. The shells were reinforced by one to four CFRP layers. Two series of shells have been tested in the experimental campaign. The shells have an average radius $R=68 \mathrm{~mm}$ for Series I and $80 \mathrm{~mm}$ for Series II, with the same height $L=150 \mathrm{~mm}$ for the two series. The thickness $t$ corresponds to the total thickness of the steel plus CFRP composite:

$$
t=t_{a}+n * t_{c}
$$

where $t_{a}$ is the steel shell thickness $\left(t_{a}=4 \mathrm{~mm}\right.$ for Series I and $t_{a}=4.5 \mathrm{~mm}$ for Series II), $n$ is the CFRP layers number applied on the external surface of the shell, and $t_{c}=0.43 \mathrm{~mm}$ is the nominal thickness of one CFRP layer. Therefore, for the unstrengthened shell Series I and Series II, plastic buckling is expected knowing that the ratio $R / t=17$ (resp. $R / t=17.8$ for Series II). The steel constitutive law is identified by the tensile tests carried out on specimens cut and machined from the steel tubes (Figure 4). The loading is an axial compression applied to the upper end shell by a hydraulic press with a maximum load capacity of $4000 \mathrm{kN}$. For the boundary conditions (Figure 3(b)), the shell is simply placed on the lower plate of the press which is clamped, and the upper plate support is free to rotate, so global rotations at the upper section of the shell are free.

3.2. Unstrengthened Shell. The study of the buckling of the unstrengthened shell allows us to confirm a progressive plastic buckling resulting by the appearance and grow of an axisymmetric wavelength (harmonic $n=0$ ), at each end of the shell (Figure 5(a)). During the collapse associated to the softening branch of the load/displacement curve (in Figure 5(b)), the buckling mode localized at one end. During the test, it is observed that axisymmetric wavelength which corresponds to the plastic bifurcation buckling mode develops first at the two extremities of the shell; then just at the limit point, only one axisymmetric wavelength continue to grows, the other one at the opposite extremity disappear a little. These 


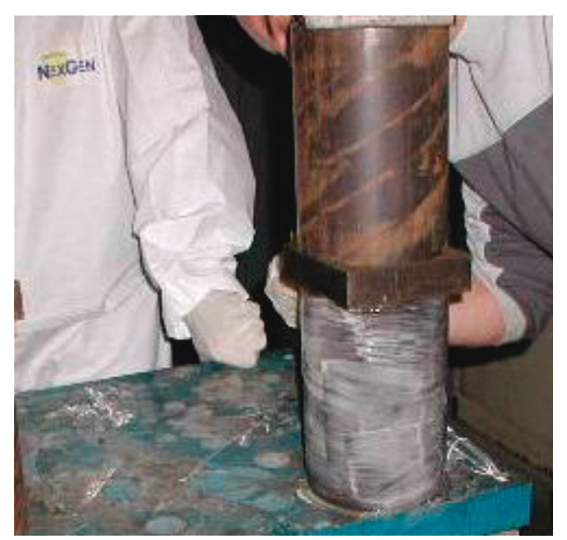

(a)

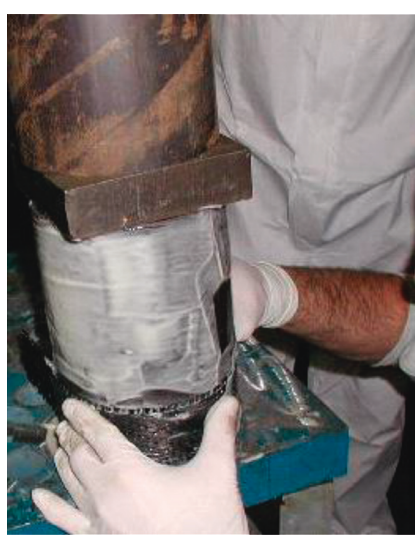

(b)

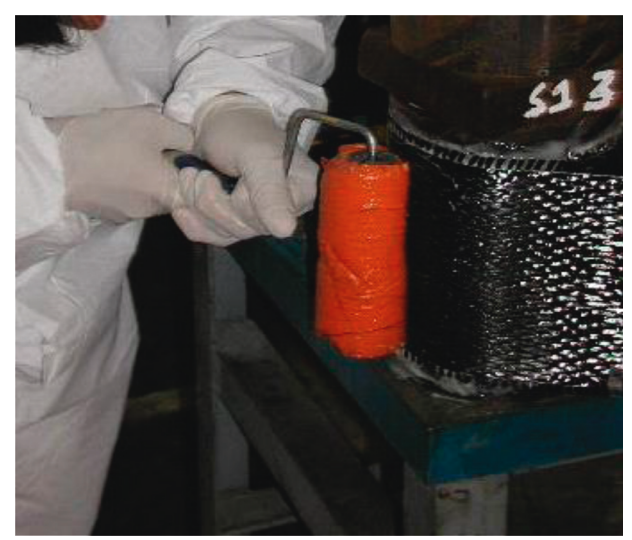

(c)

FIgURE 1: Bonding of CFRP.
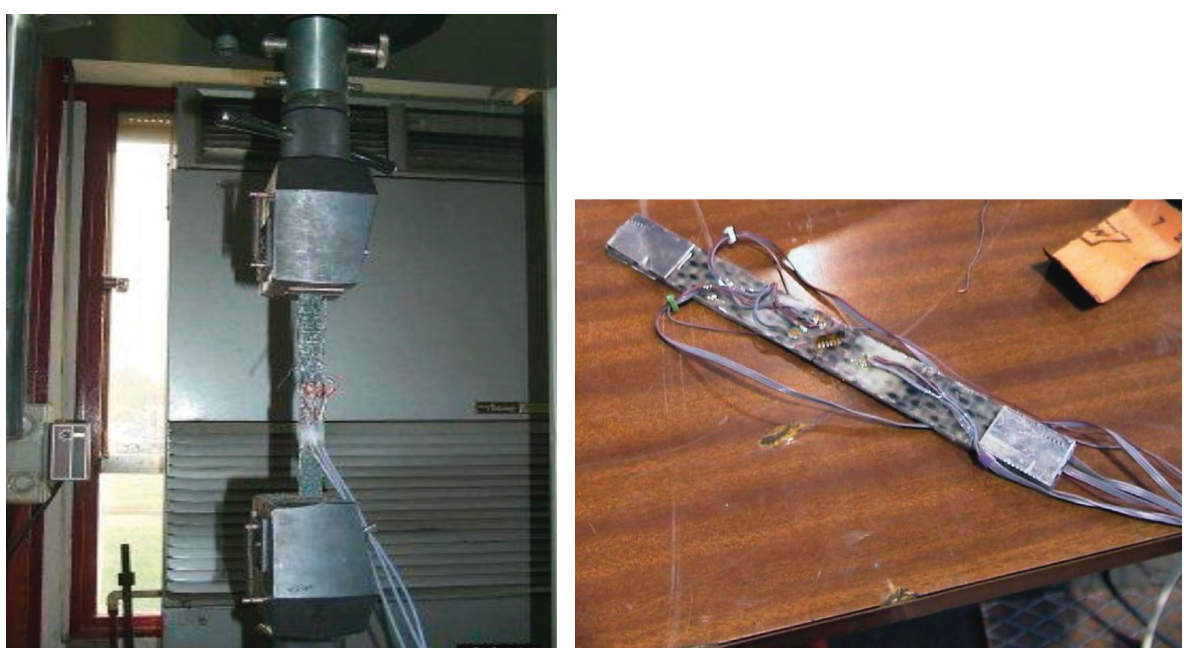

(a)

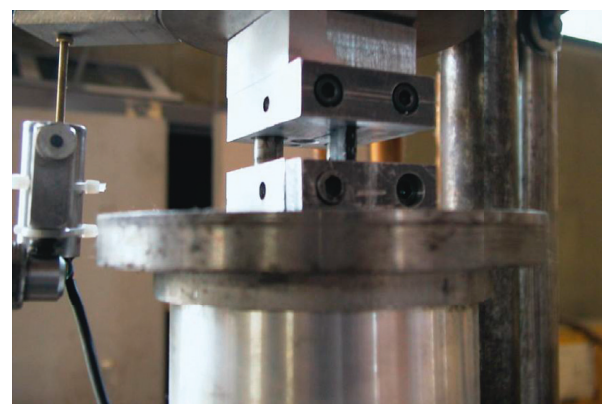

(b)

Figure 2: (a) Tension: test setup and specimen; (b) compression: test setup.

observations are in accordance with studies by Goto and Zhang [15] and Al Galib and Limam [16]. In the postcritical part of the load shortening curve, after the limit point, the elephant foot bulge (axisymmetric mode) at one extremity grows more rapidly which corresponds to mode localization as described and explained by Bardi and Kyriakides [17]; then a 2 nd critical mode associated to section ovalization (mode $n=2$ ) begins to grow at the level of the section which goes radially inward, just near the external axisymmetric bulge or elephant foot mode. The test was then stopped, knowing that the load deflection curve began to decrease and the bearing capacity of the shell was passed.

In our test, the ovalization of the section develops also at the upper part of the shell at the level of the boundary section, knowing that the radial displacement at the boundary is not perfectly clamped. The mode 2 , which appear as a second bifurcation during the softening part of the load deflection curve, as observed also for some tests and reported by Bardi 
TABLE 1: Characterization of CFRP composite.

\begin{tabular}{|c|c|c|c|c|c|c|}
\hline & \multicolumn{3}{|c|}{ Tension } & \multicolumn{3}{|c|}{ Compression } \\
\hline & Modulus & $\begin{array}{c}\text { Average } \\
\text { ultimate stress }\end{array}$ & $\begin{array}{l}\text { Ultimate } \\
\text { strain }\end{array}$ & Modulus & $\begin{array}{c}\text { Average } \\
\text { ultimate stress }\end{array}$ & $\begin{array}{c}\text { Ultimate } \\
\text { strain }\end{array}$ \\
\hline Warp direction & $\begin{array}{c}E_{l}^{\text {th }}(\mathrm{MPa}) \\
104700\end{array}$ & $\begin{array}{c}\sigma_{l}^{\text {th }}(\mathrm{MPa}) \\
1440\end{array}$ & $\begin{array}{c}\varepsilon_{l}^{\text {th }}(\%) \\
1.46\end{array}$ & $\begin{array}{c}E_{l}^{\text {th }}(\mathrm{MPa}) \\
11400\end{array}$ & $\begin{array}{c}\sigma_{l}^{\text {th }}(\mathrm{MPa}) \\
365\end{array}$ & $\begin{array}{c}\varepsilon_{l}^{\text {th }}(\%) \\
2.65\end{array}$ \\
\hline Weft direction & $\begin{array}{c}E_{t}^{\text {th }}(\mathrm{MPa}) \\
44700\end{array}$ & $\begin{array}{c}\sigma_{t}^{\text {th }}(\mathrm{MPa}) \\
290\end{array}$ & $\begin{array}{c}\varepsilon_{t}^{\text {th }}(\%) \\
0.90\end{array}$ & $\begin{array}{c}E_{t}^{\text {th }}(\mathrm{MPa}) \\
12000\end{array}$ & $\begin{array}{c}\sigma_{t}^{\text {th }}(\mathrm{MPa}) \\
280\end{array}$ & $\begin{array}{c}\varepsilon_{t}^{\text {th }}(\%) \\
2.36\end{array}$ \\
\hline $45^{\circ}$ direction & - & - & - & $\begin{array}{c}G_{45}^{\text {th }}(\mathrm{MPa}) \\
5645\end{array}$ & - & - \\
\hline
\end{tabular}

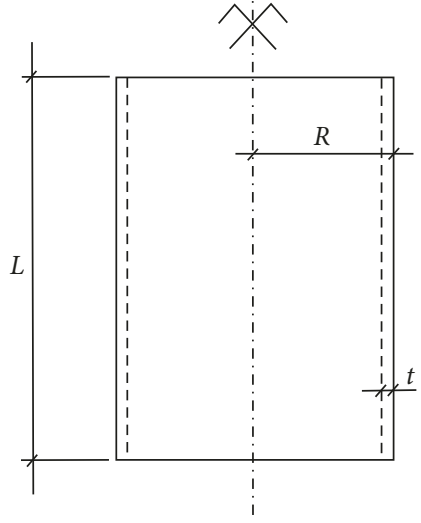

(a)
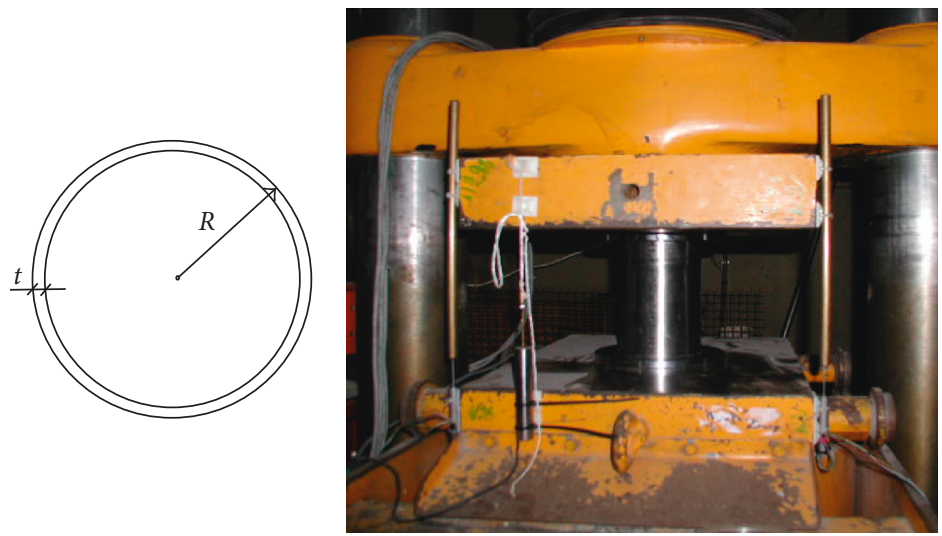

(b)

FIGURE 3: (a) Geometry characteristics of specimens tested; (b) boundary conditions (simply supported).

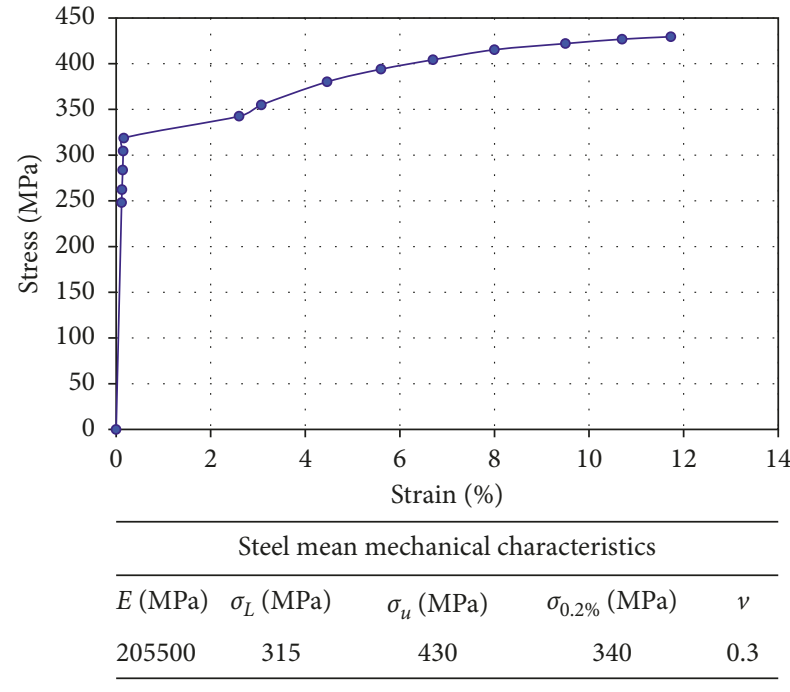

FIgURE 4: Tensile curve and mean characteristics of mild steel.

and Kyriakides [17], is then accentuated by these imperfect boundary conditions (the radial displacement is not exactly clamped).

According to the provided cross-sectional dimension of the shell and yield stress ( $315 \mathrm{MPa}$ ) of the constitutive material, the axial yield capacity of the compressed cylinder was estimated as $522 \mathrm{kN}$ and clearly shown in Figure 5(b). Therefore, it is expected that buckling of the cylinder will occur after yielding was achieved. Knowing that $R / t=17$, plastic buckling is expected, which means that yielding of the material occurs before the buckling. Moreover, the yielding zone corresponds to the entire length of the shell and not only confined near the boundary condition.

The setting up of the composite aims essentially for a gain on the bearing capacity. The objective is therefore to block or delay the onset and the evolution of the critical mode. The strengthening in the axial direction cannot lead to a substantial gain. Firstly, the compression stiffness of selected composite is low compared to the steel layer. Secondly, the progressive plastic buckling involves an important radial evolution of the displacement on zero mode or axisymmetric localized mode near the boundary. This kind of buckling mode known as "extensional modes," conducts to an important circumferential strain and to an equivalent Von Mises stress equal to the yielding limit at the beginning of the buckling process and far from the stress corresponding to the yielding plateau (strain hardening part of the curve) for the final buckling or collapse of the shell. The optimum direction or warp direction is therefore positioned at the shell circumference to induce a confinement which will limit the radial expansion of the buckling mode and plastic strain.

3.3. Case Where the Multilayered Stiffening Is Not Efficient. The preliminary tests have permitted to identify the most critical parameters. The delamination of the interlayer and steel/composite essentially occurs when the compression load is applied directly to the composite reinforcement 


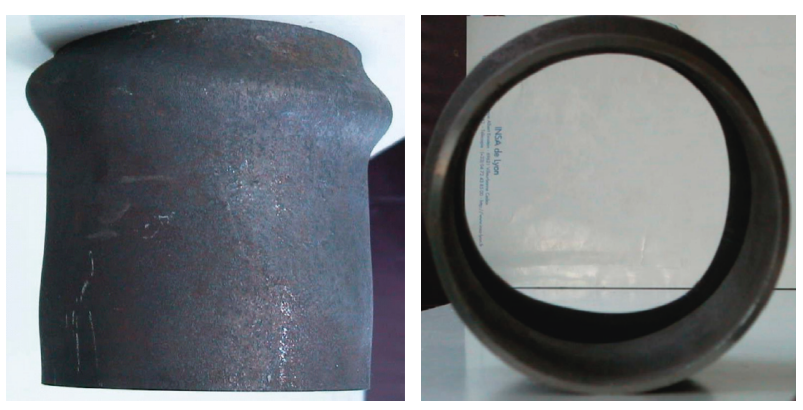

(a)

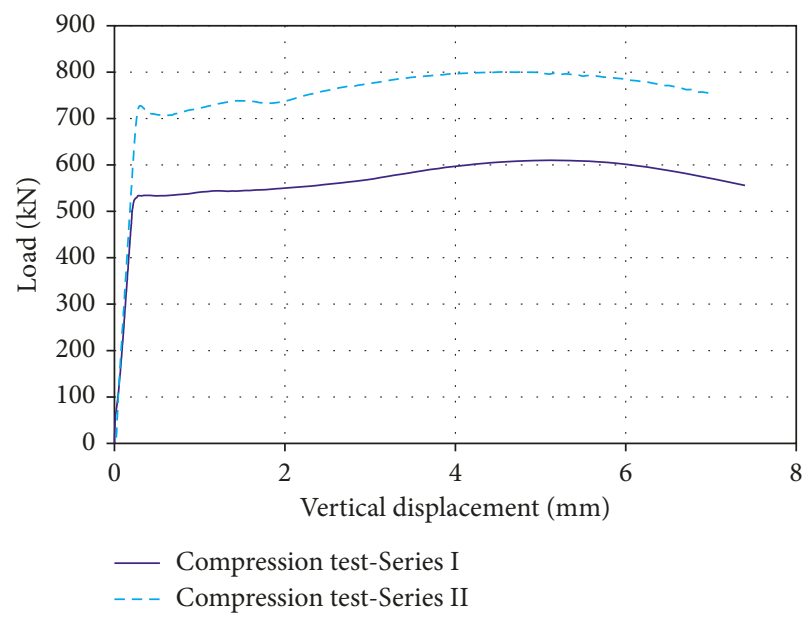

(b)

Figure 5: Unstrengthened shell: (a) extensional axisymmetric mode $(n=0)$; (b) load/displacement curve.

(in this case, the damage of the composite layer is immediate) (Figure 6(a)) or when the circumferential covering length of one layer is insufficient (Figure 6(b)). In this case, the induced gain on the buckling load is zero. To avoid these pathologies, the reinforcement does not cover the total length of the shell but stops at a distance $\delta=2.444 \sqrt{R t}$ from the shell edge $[18,19]$. This distance corresponds to the length, at each extremity of the shell, perturbed by bending stress caused by the boundary conditions. Far from this region, the shell supports only membrane stresses.

\subsection{Behavior of the Steel/CFRP Multilayered Shell. The} mechanical behavior of the shell strengthened by two CFRP layers can be characterized by three phases as described in Figure 7. The first branch (1) traduces essentially the membrane behavior, here insensitive to the strengthening because the added membrane stiffness is negligible comparatively to the metallic shell rigidity. Then a nonlinear behavior (2) translates the interaction of the geometric nonlinearity, or beginning of large displacements related to buckling, and material nonlinearity or steel yielding. The brutal drops in loading (3) correspond to the fiber ruptures (dynamic effect). These localized damages of CFRP conduct to stress redistributions once again allowing a loading increase. For all tested reinforcement configurations (Figure 8), the composite allows an increase of the bearing capacity, with more than $30 \%$ gain for three layers. Starting from three layers, the buckling mode changes; the axisymmetric extensional mode gives way to inextensional nonaxisymmetric modes as mode 3 or mode 4 .

3.5. Effect of Steel/CFRP Adhesion. The problem of steel/CFRP adhesion is one of the concerns in which this study wanted to answer. For the reinforcement to be effective, is it necessary to have the adhesion on the metal shell? Or is the contact enough, even if slip is permitted? The question is legitimate, because metal tanks or silos do not always have the same surface state. Mild steel, stainless steel, or aluminum does not have the same surface roughness. Moreover, a surface paint can completely change this roughness. Sometimes, the cleanliness of the surface, necessary to the development of the adhesion, is not guaranteed. In several cases, the presence of hydrocarbons or oil or even corrosion products can strongly affect the adhesion locally, and this imperfection can spread in time. Therefore, it seems essential to evaluate the contribution of the CFRP in the case where there is no adhesion. That's why appropriate experimental tests dedicated to this configuration without adhesion were studied.

To gauge the adhesion effect of the reinforcement on the metal, two configurations were tested (only for Series II). For the first configuration, the reinforcement is applied directly on the steel, while for the second one, the presence of a plastic film prevents the bond of CFRP on the steel (Figure 9). Tests show that the bearing capacity is then unchanged, with about 3\% differences, although the precritical behavior differs (Figures 10 and 11). In the case of nonadhesion, the role at the interface delays the tension appearance of the composite, which is initiated from the beginning of loading (Poisson effect) in the case with adhesion. When the mode is progressed sufficiently, the steel comes into contact with the composite, and the steel/composite multilayer functions as in the case of perfect adhesion (Figures 10 and 11). Furthermore, the linear part does not change. There is a difference between the perfect adhesion and nonadhesion case but at the initiation of the nonlinear phase. With adhesion, the composite band effectively works earlier and works harder to decrease (delay) the radial expansion (buckling) and therefore to increase the effort. However, it seems that the strengthening in the nonadhesion case can achieve higher ultimate loads. But this type of strengthening without adhesion allows the shell to initiate a buckling mode that could cause, in some cases, the ruin of the structure before the CFRP goes into action. The implementation of CFRP with adhesion gives slightly lower results in terms of ultimate load, but the CFRP works as soon as the charging of the structure and thus provides a guarantee to preserve the functionality of the structure by avoiding the initiation of buckling.

After adjustment (Figure 12), it is noted that the rigidities perfectly overlap from the moment that the radial evolution guarantees the tension appearance of the composite. These tests have allowed us to conclude that the steel/composite bonding is not fundamental in terms of 


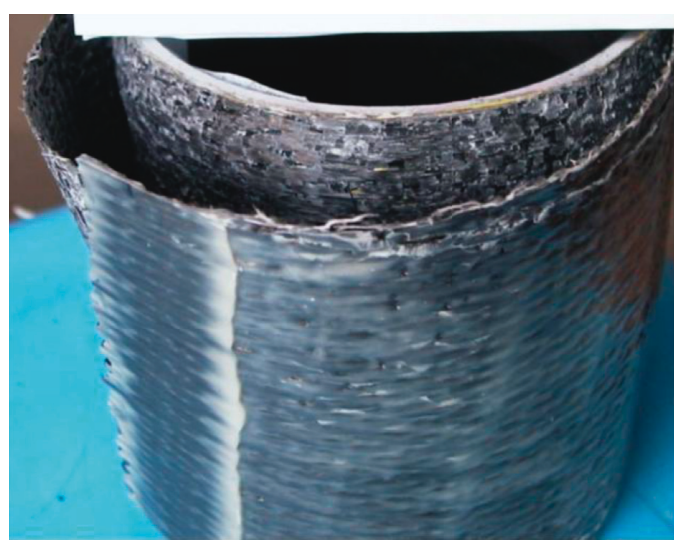

(a)

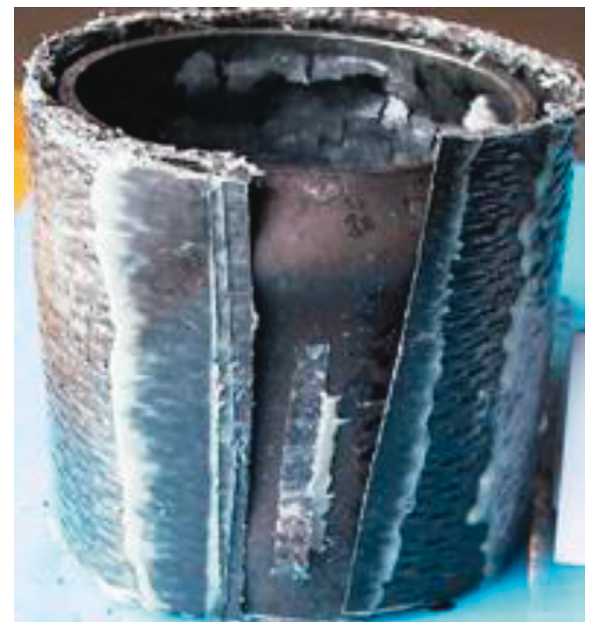

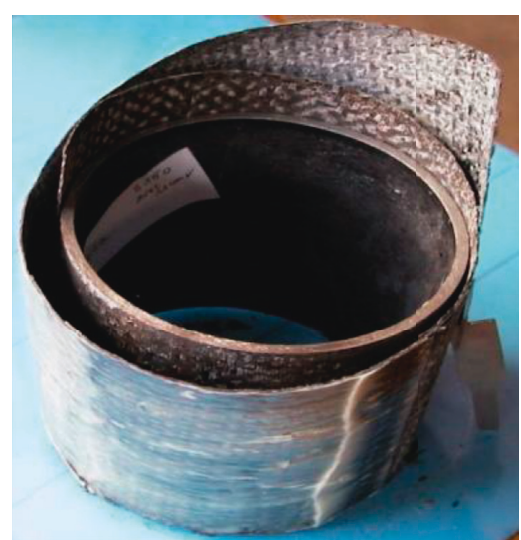

(b)

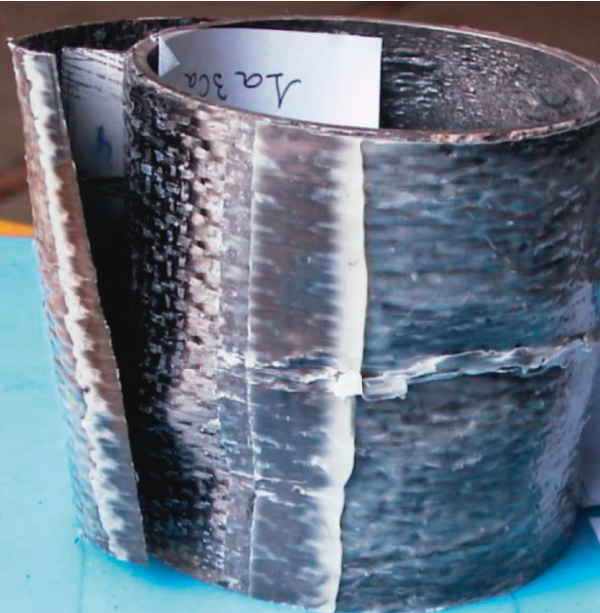

(c)

Figure 6: (a) Damage to the steel/composite interface; (b) interlayer delamination due to localized loading on CFRP; (c) null or insufficient covering conducts to inhibit "belt effect" of the CFRP layer.

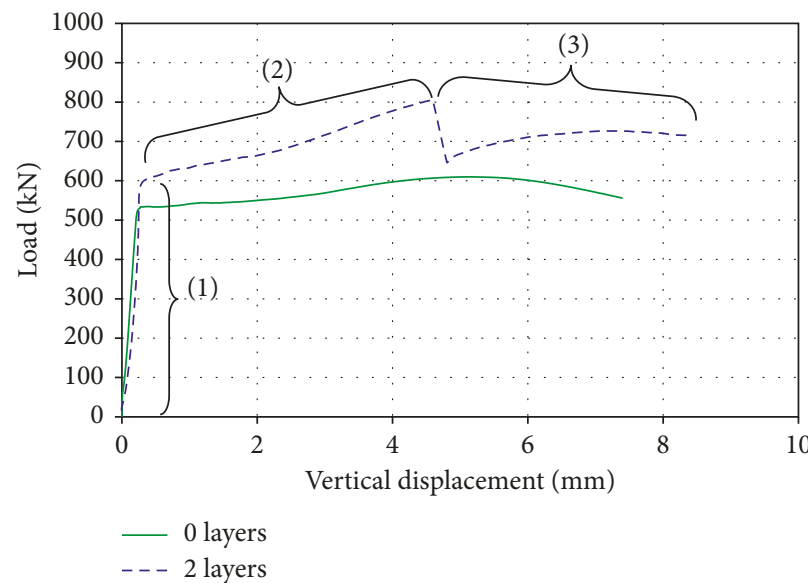

(a)

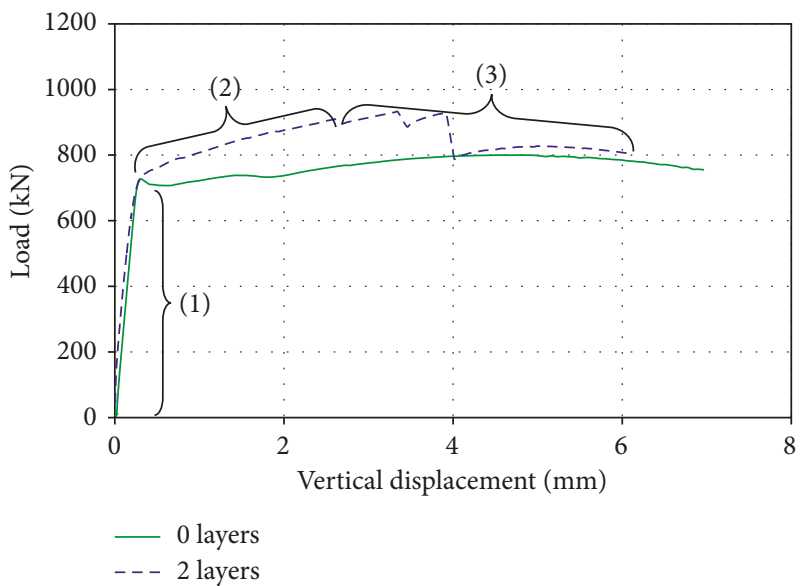

(b)

FIGURE 7: Load-deflection curves and mechanical behavior of unstrengthened and strengthened configurations. (a) Series I. (b) Series II.

bearing capacity. Then, for estimation of the bearing capacity using a numerical model, assuming perfect bonding seems relevant. Note that in the nonadherent case, the composite damage is delayed. This therefore allows a slight supplementary gain compared to the adherent case (between 1\% and $10 \%)$. 


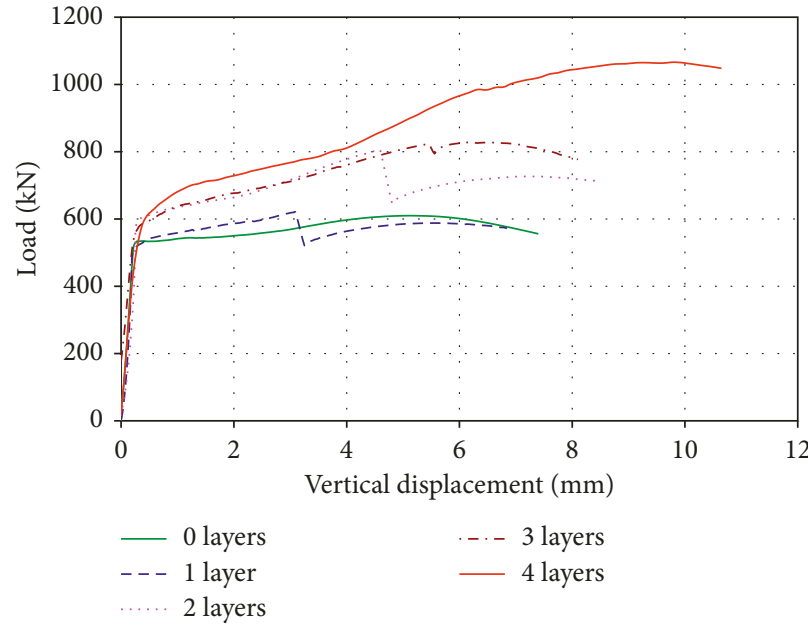

(a)

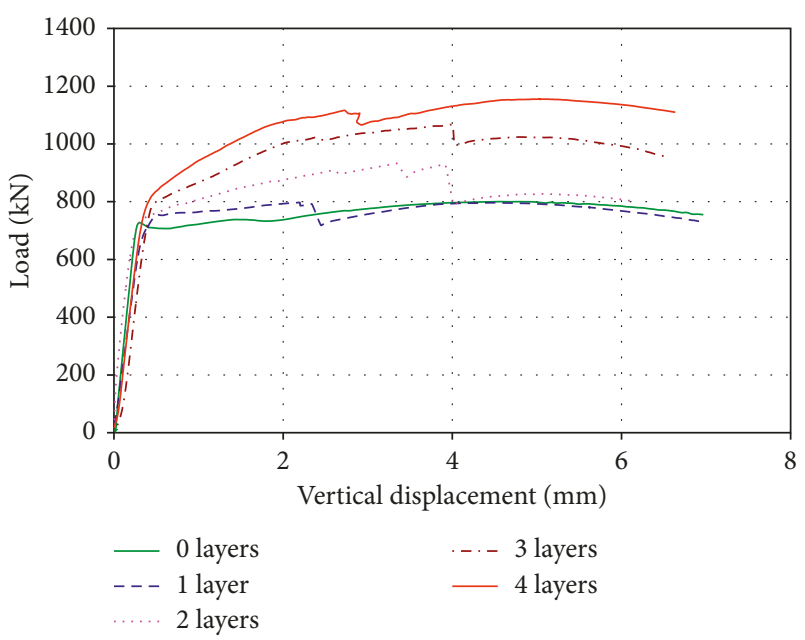

(b)

FIGURE 8: Load/displacement curves: effects of the number of layers. (a) Series I. (b) Series II.

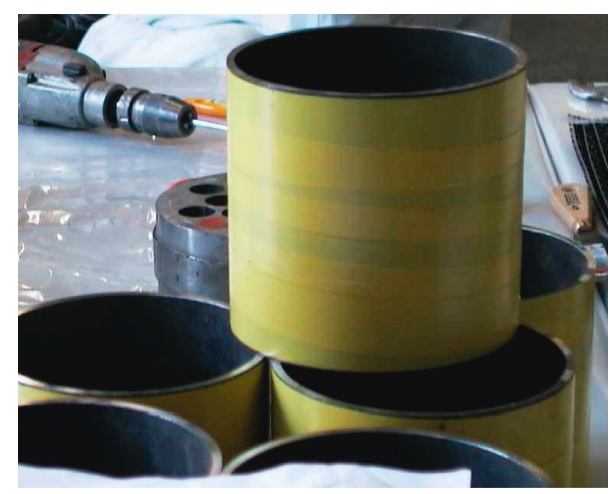

FIgUre 9: Application of a plastic film on external surface of the metal shell.

\section{Numerical Simulation and Interpretations}

4.1. Numerical Model. Numerical simulations are conducted with ABAQUS finite element code. The S8R shell element, based on Koiter-Sanders shell theory, is well adapted for thin or intermediate thick shells. The steel and the CFRP have been modelled by the multilayer S8R shell element. The multilayer shell type approach has been chosen to exclude the interface problems, as perfect bonding of the composite layer to the steel layer is considered and debonding or interface damage are excluded. The CFRP is modelled by an external $0.43 \mathrm{~mm}$ thickness layer, perfectly bonded to a $4 \mathrm{~mm}$ thick steel shell layer. For the case strengthened with several layers of CFRP, the layers number considered in the numerical model is equal to the one used in the experimental test. The perfect adhesion was also assumed between the CFRP layers. As Figure 13 shows, only a quarter of the shell is meshed, knowing that plastic bifurcation analysis conducted on the whole shell shows that the potential critical modes are mainly modes 0 and 4 .

The boundary conditions are the symmetry on both vertical edges; this choice is compatible with the expected buckling mode in the unstrengthened case or strengthened case with one or two layers (axisymmetric mode). In the case of the buckling with a nonaxisymmetric mode, this hypothesis remains valid. It is confirmed by a calculation with the antisymmetric conditions on one or both vertical edges. The shell base is clamped, as well as the upper part where only Uz (vertical displacement) is free. The incremental calculation is thus carried out in imposed displacement in order to be able to pass the limit point.

The constitutive law behavior of materials is defined by layer. For mild steel, an elastoplastic law with isotropic hardening was considered. Although the finite element model is based on a $2 \mathrm{D}$ mesh model, the updating of the thickness has been taken into account. This artifice is necessary in the case of the large deformations inherent to the critical behavior associated with progressive plastic buckling. The radial evolution of the axisymmetric bulge which traduces the progressive plastic buckling leads to circumferential strains about $5 \%$. For the CFRP, an orthotropic elastic behavior was considered. Neither the ultimate stress nor the various damages (fibers ruptures) that precede the critical threshold or layer failure are considered here. The consideration of damage associated to fibers failure or layers delamination or failure will be the object of a further studies.

4.2. Unstrengthened Shell. The numerical simulation confirms the buckling on axisymmetric mode or elephant foot mode. Axisymmetric wavelength develops at each end of the structure. In the initial linear phase, the behavior is classic with the "barrel effect" or Poisson effect; then the axisymmetric wave appears and evolves to the plastic hinge which corresponds to the limit point.

The correlation between experiment and simulation is quite good in terms of initial behavior (precritical), ultimate load (deviation is $<1 \%$ ), and critical mode (Figure 14). After the plateau which corresponds to achievement of ductility plateau in terms of stresses, the experiment/simulation curves deviate. This can be explained by the experimental boundary conditions which do not correspond to perfect 


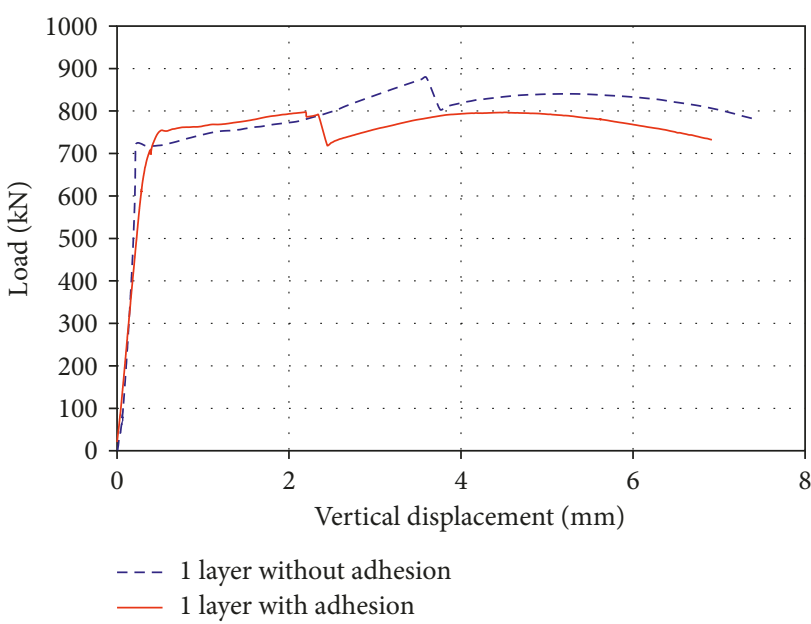

(a)

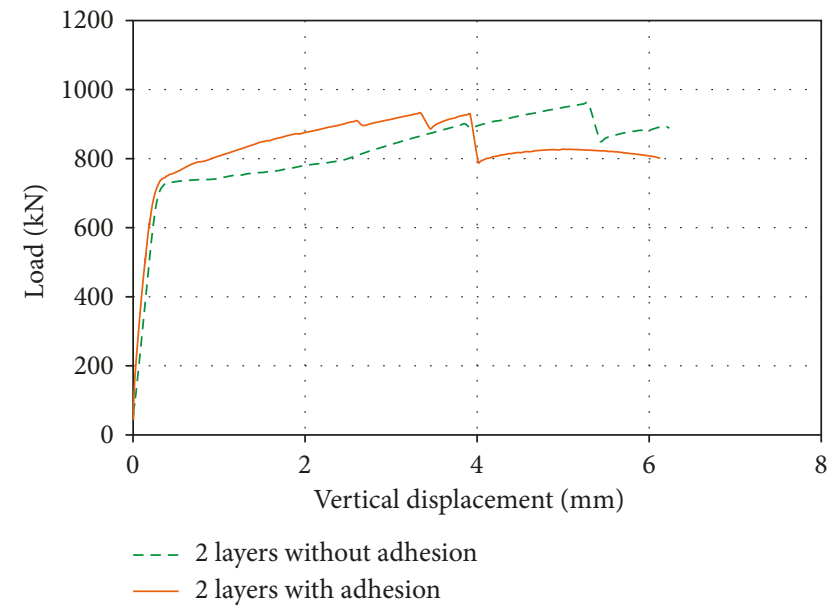

(b)

FIgURE 10: Effect of adhesion for 1 and 2 CFRP layers-Series II

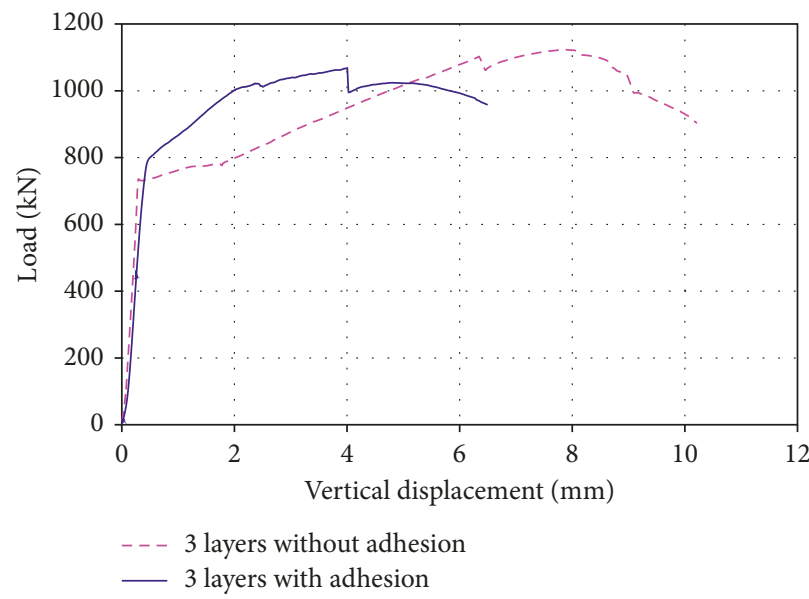

(a)

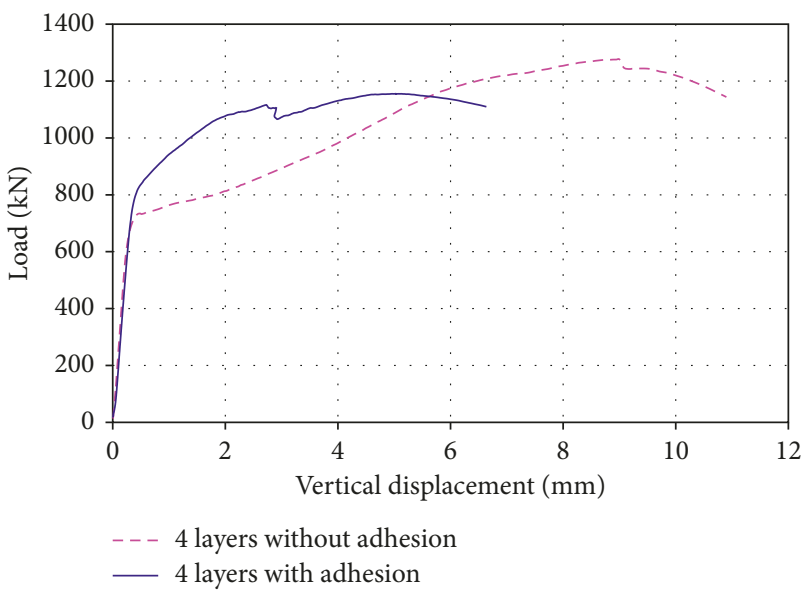

(b)

FIgURE 11: Effect of adhesion for 3 and 4 CFRP layers-Series II.

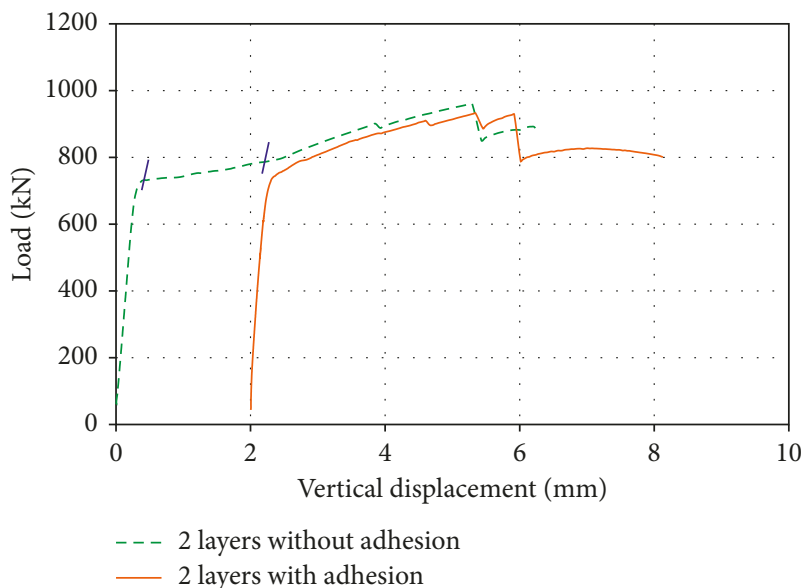

Figure 12: Adjustment of postcritical behavior-Series II. embedding. The amplification of the axisymmetric mode, as well as the imperfections of the boundary conditions, induces the appearance of the ovalization mode $n=2$. During the test, a mode $n=0$ was obtained on both sides of the shell structure, but during the collapse (softening branch), there was localization of the axisymmetric mode at only one extremity (Figure 5), and the wavelength at the other side disappears.

4.3. The Strengthened Shell. In the case of reinforcement with one and two layers of CFRP, the calculations perfectly reproduce the first elastic branch, the beginning of plasticity, the first part of the nonlinear behavior, and the buckling mode (Figures 15 and 16). The experiment/simulation difference appears as soon as there is a localized rupture failure of the CFRP which is not taken into account in our basic model. 


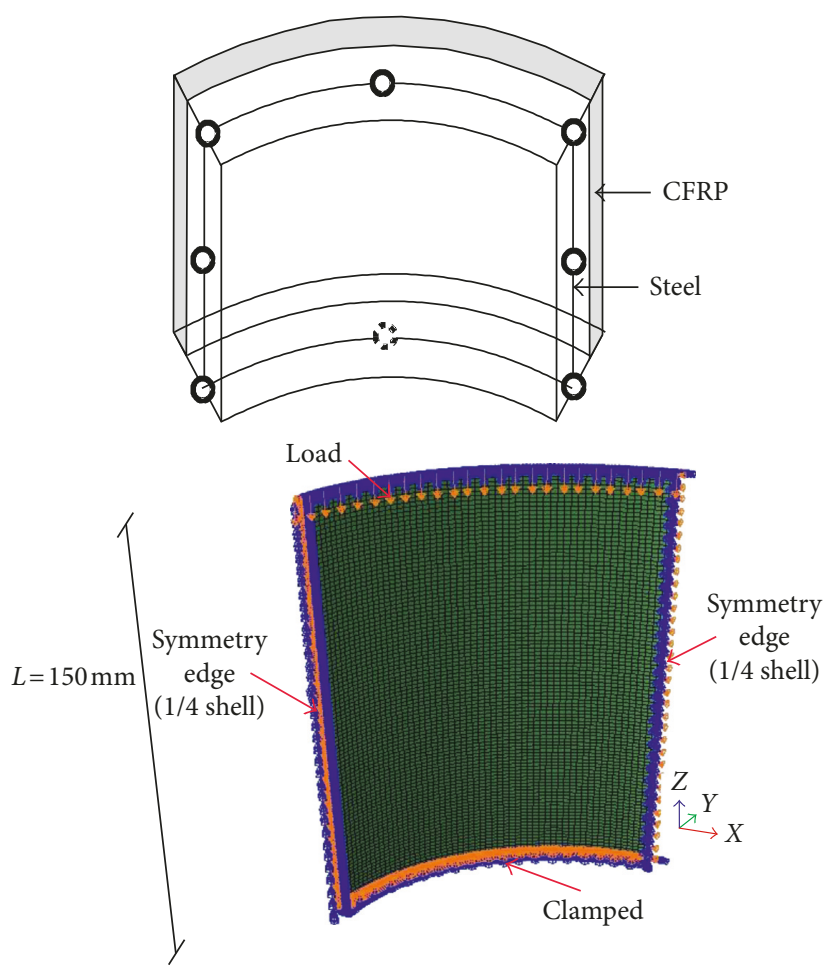

FIGURE 13: The multilayer shell model.

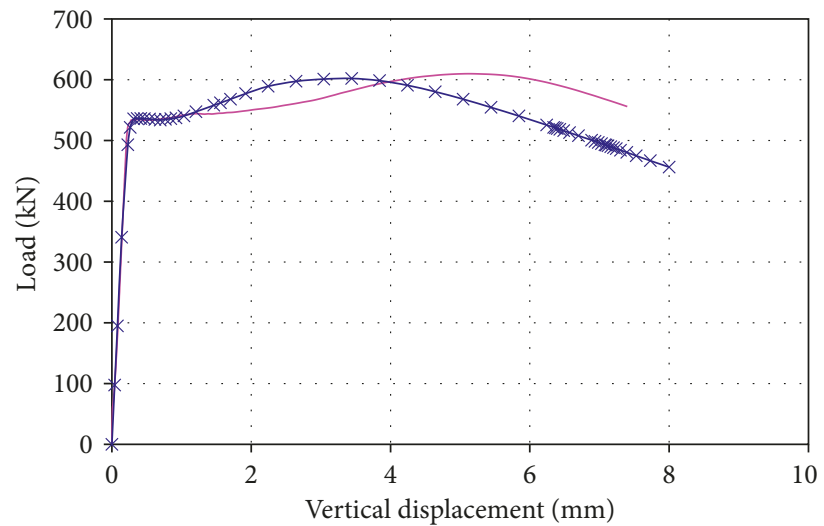

- Experiment

$\rightarrow$ Numerical simulation

(a)

$S$, mises

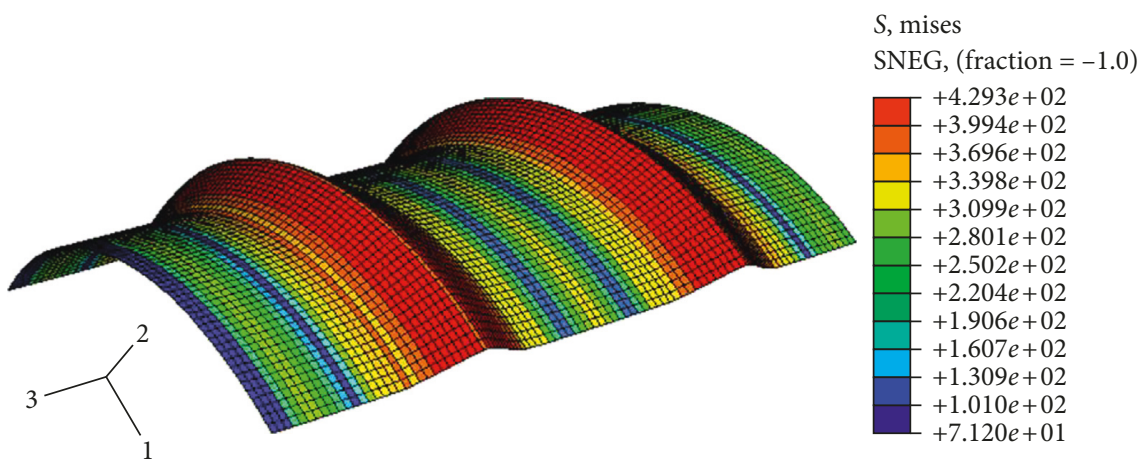

(b)

FIGURE 14: Unstrengthened shell-Series (I) comparison of experiment/simulation behavior and numerical buckling mode. 


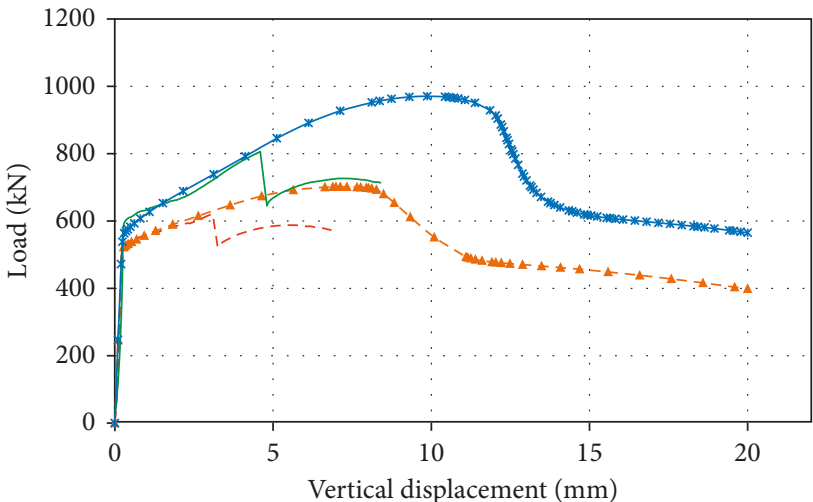

---1 layer-experiment $\quad 2$ layers-experiment
$-\ldots-1$ layer-simulation $\quad-2$ layers-simualtion

(a)

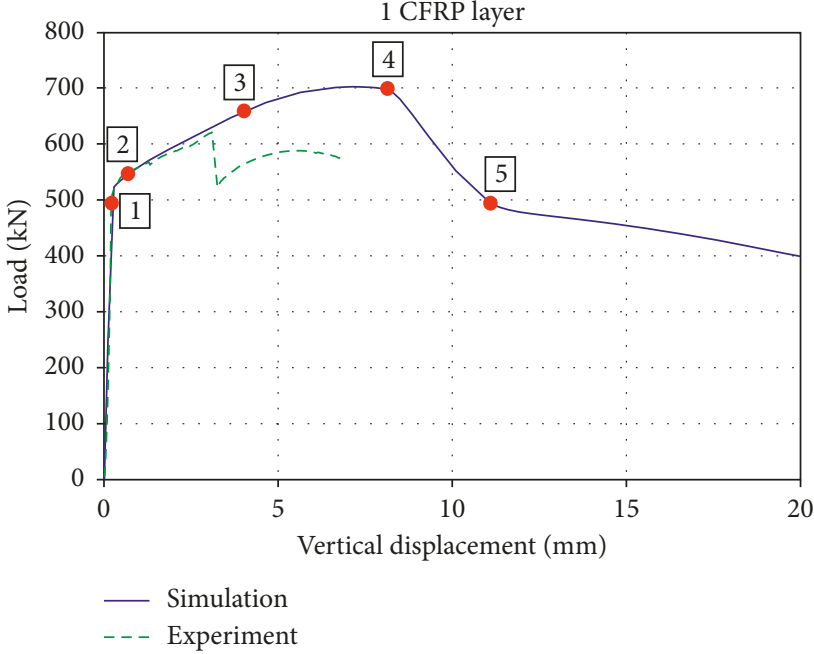

(b)

FIGURE 15: Numerical and experimental load/displacement curves.

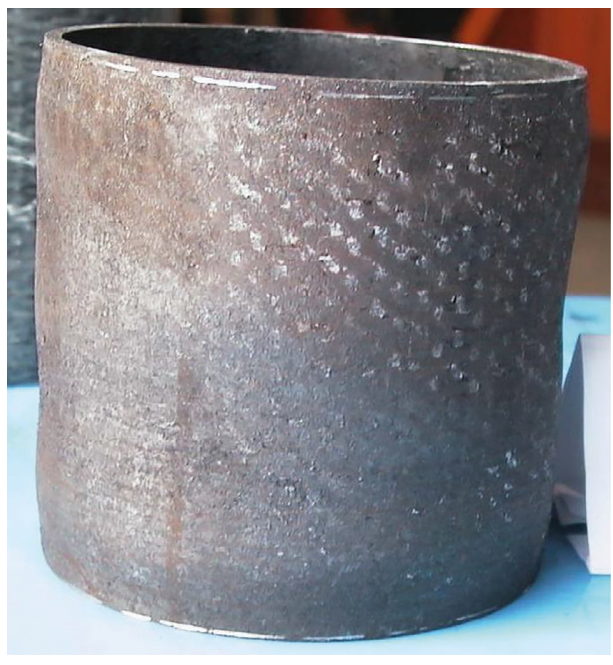

(a)

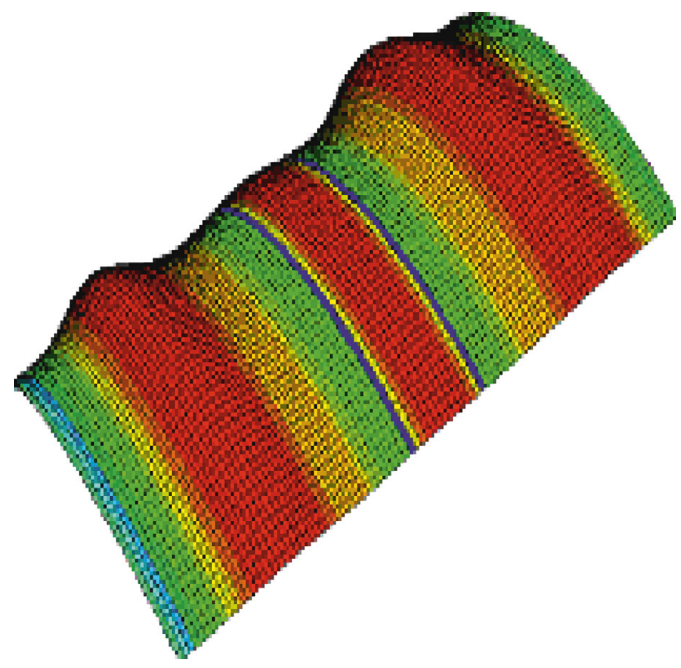

(b)

FIGURE 16: Experimental obtained extension mode (composite removal) and numerical one (Von Mises stresses in the steel layer) of one and two layers of CFRP.

In the experimental curve, this local failure conducts to a drop of the bearing capacity, but a redistribution of the stress conducts to a possible increase again of the loading process, but the reserve or possible increase of the load is limited, and the initial maximal load sustained cannot be reached again. But the ductile collapse of the shell characterized by damage evolution through the composite layers is noticed (fibers failure is clearly noticed here). Knowing that the numerical model does not take into account local failure of fibers and damage at the interface of the layers of the composite, the calculations, therefore, overestimate the structure capacity.

For the case of one-layer CFRP reinforcement, stress and strain state of the multilayer (steel/CFRP) were analysed for different reference points positioned on the load/deflection curve (Figure 15(b)). The warp direction which corresponds to the circumferential direction of the shell was mainly
TABLE 2: Numerical stresses and strains for each layer.

\begin{tabular}{ccccccc}
\hline \multicolumn{2}{c}{ Five reference points } & 1 & 2 & 3 & 4 & 5 \\
\hline \multirow{2}{*}{ Steel layer } & $\sigma_{\mathrm{Z}}(\mathrm{MPa})$ & 319.2 & 321.2 & 392.2 & 430 & 430 \\
& $\mathcal{E}_{\mathrm{Z}}(\%)$ & 0.069 & 0.18 & 1.4 & 3.6 & 5.1 \\
\hline \multirow{2}{*}{ CFRP layer } & $\sigma_{\theta}(\mathrm{MPa})$ & 65.3 & 172.4 & 1440 & 3799 & 4971 \\
& $\varepsilon_{\theta}(\%)$ & 0.069 & 0.18 & 1.4 & 3.6 & 5.1 \\
\hline
\end{tabular}

chosen to analyse stress and strain states; the CFRP thus works essentially in traction. Deformations and stresses $\left(\varepsilon_{\theta}\right.$, $\sigma_{\theta}$ et $\left.\varepsilon_{Z}, \sigma_{Z}\right)$ supported, respectively, by the CFRP layer and the steel layer are given in Table 2 .

Table 2 shows that when the steel yields, the CFRP undergoes a circumferential stress induced by the initiation of buckling which allows delaying the evolution of the mode 

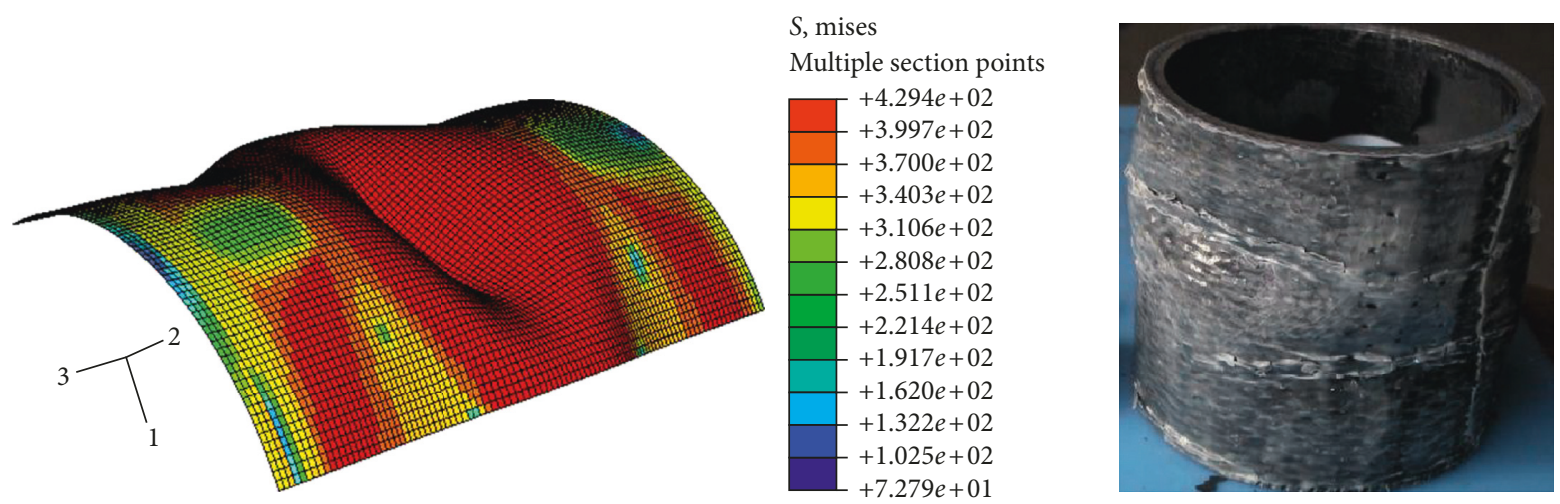

(a)

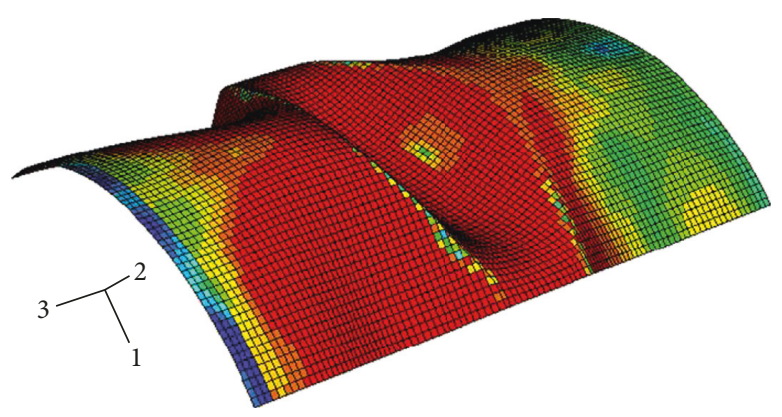

$S$, mises

Multiple section points
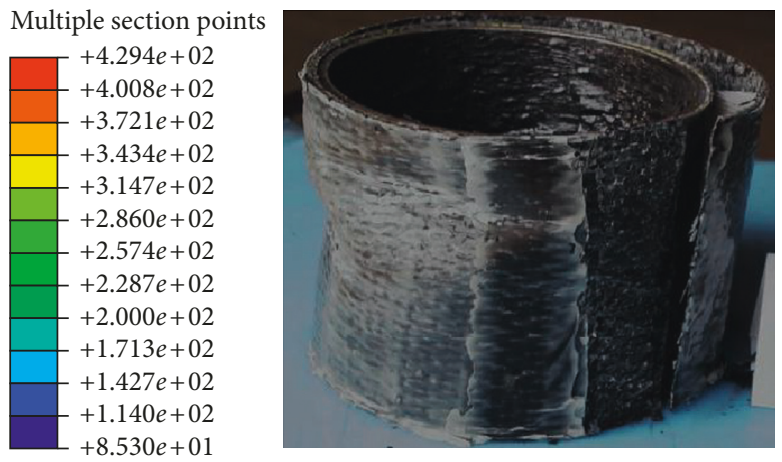

(b)

FIGURE 17: Numerical and experimental inextensional buckling mode: (a) 3 CFRP layers; (b) 4 CFRP layers.

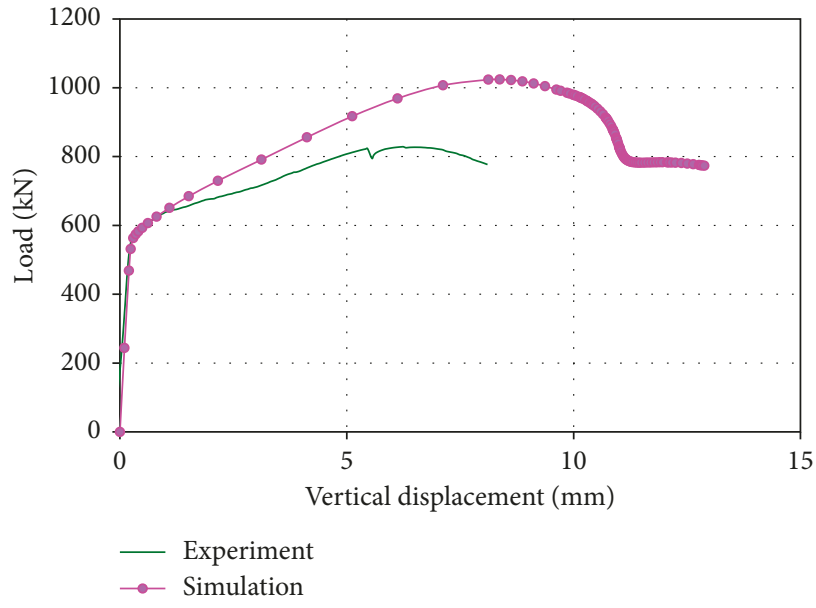

(a)

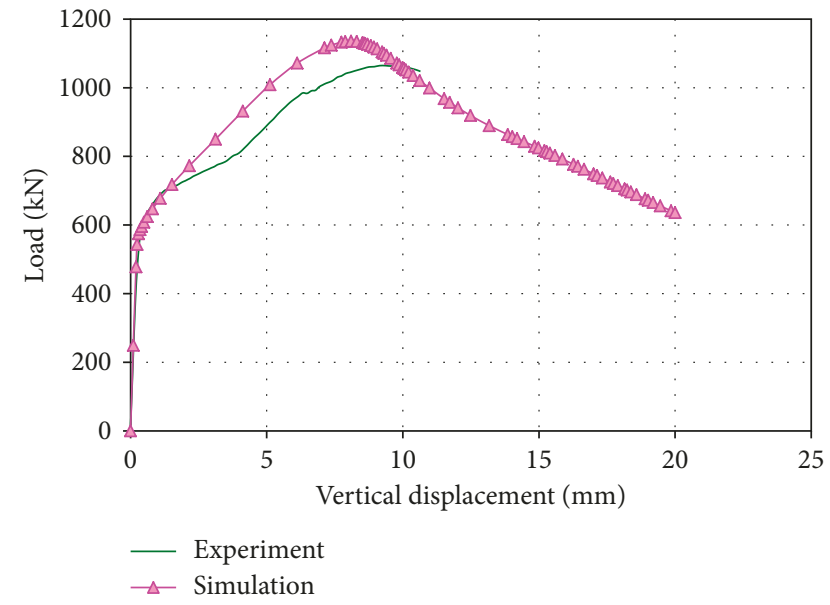

(b)

Figure 18: Experiment and simulation: (a) 3 CFRP layers; (b) 4 CFRP layers.

(point number 1 and number 2). At point number 4, the steel reaches the ultimate stress but not the ultimate deformations $\left(\sigma_{u}=430 \mathrm{MPa}\right.$ obtained from the steel tensile curve, see Figure 4), and the CFRP reaches the ultimate stress (rupture) at the point number $3\left(\sigma_{l}^{\text {th }}=1440 \mathrm{MPa}\right.$ obtained from Table 1). Therefore, if the ultimate state of the composite (failure) was taken into account in the numerical model, instead of the actual perfectly elastic chosen model, the collapse will be around point number 3 , and consequently the tests can be better correlated. We recall that in our numerical model, composite failure is not taken into account. Therefore, in the future work, the numerical model should be enriched in order to catch CFRP progressive damage until the failure. 


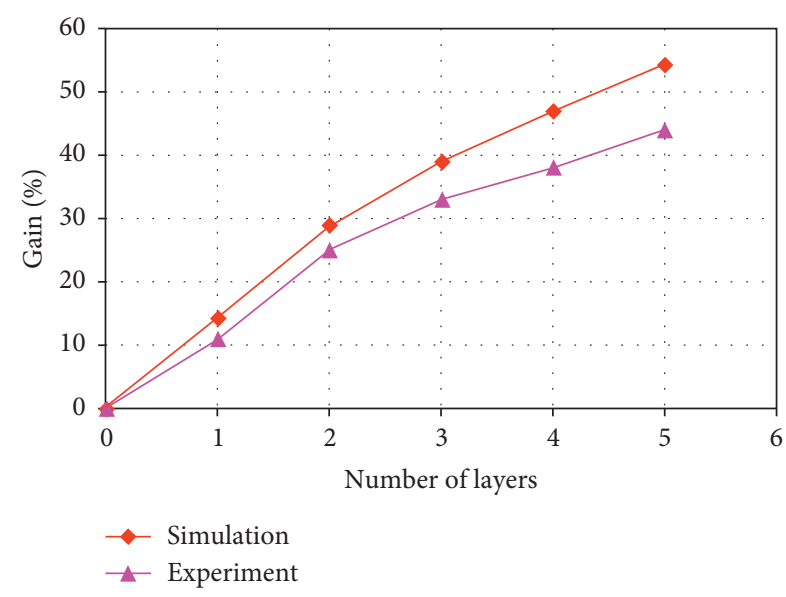

FIgURE 19: Bearing capacity gain function of the CFRP layers-experiment/simulation.

In the case of strengthening with three or more layers of CFRP, the numerical model associated to incremental calculation (Newton-Raphson) does not detect the bifurcation in the third or fourth mode observed experimentally. Even Riks calculation failed to catch the bifurcated branch equilibrium. In order to better correlate the numerical results to the experiments in the strengthening case involving three or more layers of CFRP, a structure perturbed by an initial defect collinear to mode 4 of the Euler bifurcation analysis has been considered. This artifice allows to correlate in part of the experimental results (Figures 17 and 18), that is, the initial rigidity and the first part of the nonlinear behavior. However, the numerical model overestimates the real strength of the strengthened structure. The nonconservative aspect of the modelling requires taking into account the various damages that the CFRP supported during the loading process (localized ruptures and localized delamination).

The gain on the bearing capacity can be described by a bilinear function of the layers number (Figure 19). The change in slope observed during the passage from two to three layers is explained by the mode change observed experimentally. For one and two layers, the axisymmetric mode guarantees essentially a membrane behavior (extensional mode). The bifurcation in a quasi-inextensional mode (mode $n=4$ ), obtained for a strengthening equal to or greater than three layers of CFRP, leads to kinematics combining membrane and flexion. Then local curvature variations favor the interlayer delamination as well as the fiber ruptures, which reduces the gain on bearing capacity.

\section{Conclusions}

This study allowed us to validate the concept of strengthened thick metallic shells using external layer of composite strip impregnated with epoxy resin. A substantial increase of the buckling load is here demonstrated.

(i) For the mild steel thick shells $(R / t=17)$ here studied, a gain more than $40 \%$ is noticed on the bearing capacity when the shell is strengthened with
3 layers of CFRP, and in the case of strengthening by five layers, the gain is higher than $40 \%$.

(ii) Starting from three layers, the buckling mode changes; the axisymmetric extensional mode gives way to inextensional mode 3 or 4 .

(iii) Knowing that for in situ reinforcement, the perfect adherence of the composite reinforcement to the steel shell cannot be systematically guaranteed, and the effect of the CFRP layer adhesion on the metal shell has been carefully studied. The conducted tests allowed us to conclude that the steel/composite bonding is not fundamental in terms of bearing capacity.

(iv) The numerical simulation, although integrating restrictive hypotheses with regard to the choice of kinematics (no delamination or metal/composite or composite/composite interface debonding) and behavior laws (no damage of composite as fiber failure was considered), leads to the results which correlate correctly the experiments, at least in the precritical domain, as well as buckling initiation. However, according to this simplified modeling, the final gain in bearing capacity induced by the CFRP reinforcement is overestimated. The numerical simulation of steel/composite multilayer shells must be improved by considering a behavior law integrating the different damages of the composite, in particular localized failure of fibers induced by tensile stress and layers delamination induced by local bending as well as fragile failure of composite layer. A model integrating these aspects is necessary for the good estimation of the bearing capacity as well as the successions of local softening and upward branches until the final collapse of the shell.

\section{Data Availability}

The data used to support the findings of this study are included within the article.

\section{Conflicts of Interest}

The authors declare that there are no conflicts of interest regarding the publication of this paper.

\section{Acknowledgments}

The authors gratefully acknowledge Freyssinet France for providing the CFRP and their technical staff for the application of the reinforcement following the recommended application procedure.

\section{References}

[1] CEN, Eurocode 8: Design of Structures for Earthquake Resistance, European Committee for Standardisation, Bruxelles, Belgium, 2013. 
[2] J. F. Chen, J. M. Rotter, and J. G. Teng, "A simple remedy for elephant's foot buckling in cylindrical silos and tanks," $A d$ vances in Structural Engineering, vol. 9, no. 3, pp. 409-420, 2006.

[3] Z. Draidi, Reinforcement and reparation of metal structures shells with composite material (CFRP): study of the buckling behavior: experimental and numerical analysis, Ph.D. thesis, SUDOC, Lyon, France, 2005, http://www.sudoc.fr/094862540.

[4] M. Batikha, J. F. Chen, J. M. Rotter, and J. G. Teng, "Strengthening metallic cylindrical shells against elephant's foot buckling with FRP," Thin-Walled Structures, vol. 47, no. 10, pp. 1078-1091, 2009.

[5] V. Morteza and S. Hossein, "Experimental and numerical investigation of elephant foot buckling and retrofitting of cylindrical shells by FRP," Journal of Composites for Construction, vol. 20, no. 4, article 04015087, 2016.

[6] H. Toutanji and S. Dempsey, "Stress modeling of pipelines strengthened with advanced composite materials," ThinWalled Structures, vol. 39, no. 2, pp. 153-165, 2001.

[7] M. K. Vistasp and S. Frieder, "Fiber reinforced compositesadvanced materials for the renewal of civil infrastructure," Applied Composite Materials, vol. 7, no. 2-3, pp. 95-124, 2000.

[8] B. Täljsten and L. Elfgren, "Strengthening concrete beams for shear using CFRP materials: evaluation of different application methods," Composites Part B: Engineering, vol. 31, no. 2, pp. 87-96, 2000.

[9] U. Meier, "Strengthening of structures using carbon fibre/ epoxy composites," Construction and Building Materials, vol. 9, no. 6, pp. 341-351, 1995.

[10] T. T. Bui and A. Limam, "Out-of-plane behaviour of hollow concrete block masonry walls unstrengthened and strengthened with CFRP composite," Composite Part B, vol. 67, pp. 527-542, 2014.

[11] A. Louhi, A. Limam, O. Merabet, and T. Rourre, "Rebar section loss and carbon fiber reinforced plastic reinforcement effects on nonlinear behavior and ultimate load of cooling towers," Engineering Structures, vol. 136, pp. 481-493, 2017.

[12] C. T. Sun, J. Klug, and C. Arendt, "Analysis of craked aluminium plates repaired bonded composite paths," AIAA Journal, vol. 34, no. 2, pp. 369-374, 1996.

[13] J. Blachut, "Use of reinforced plastics to restore the buckling strength of imperfection sensitive silos," in Proceedings of Imperfection in Metal Silos Workshop, Lyon, France, April 1996.

[14] G. D. Galletly, D. N. Moreton, and A. Muc, "Buckling of slightly flattened domed ends reinforced locally with fibrereinforced plastic," Proceedings of the Institution of $\mathrm{Me}$ chanical Engineers, Part E Journal of Process Mechanical Engineering, vol. 204, no. 1, pp. 15-24, 1990.

[15] Y. Goto and C. Zhang, "Plastic buckling transition modes in moderatly thick cylindrical shells," Journal of Engineering Mechanics, vol. 125, no. 4, pp. 426-434, 1999.

[16] D. Al Galib and A. Limam, "Global bending and or local buckling: towards a better characterization of the crushing behavior of cylindrical shells," in Proceedings of the Third International Conference on Coupled Instabilities in Metal Structures CIM'S 2000, D. Camotim, D. Dubina, and J. Rondal, Eds., pp. 21-23, Lisbon, Portugal, September 2000.

[17] F. C. Bardi and S. Kyriakides, "Plastic buckling or circular tubes under axial compression-Part 1: experiments," International Journal of Mechanical Sciences, vol. 48, no. 8, pp. 830-841, 2006.
[18] P. A. Berry, J. M. Rotter, and R. Q. Bridge, "Compression tests on cylinders with circumferential weld depressions," Journal of Engineering Mechanics, vol. 126, no. 4, pp. 405-413, 2000.

[19] J. G. Teng and J. M. Rotter, "Buckling of pressurized axisymmetrically imperfect cylinders under axial loads," Journal of Engineering Mechanics, vol. 118, no. 2, pp. 229-247, 1992. 


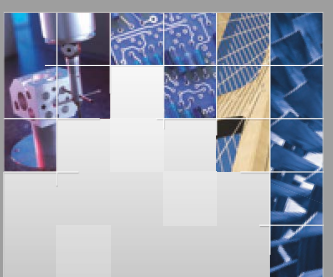

\section{Enfincering}
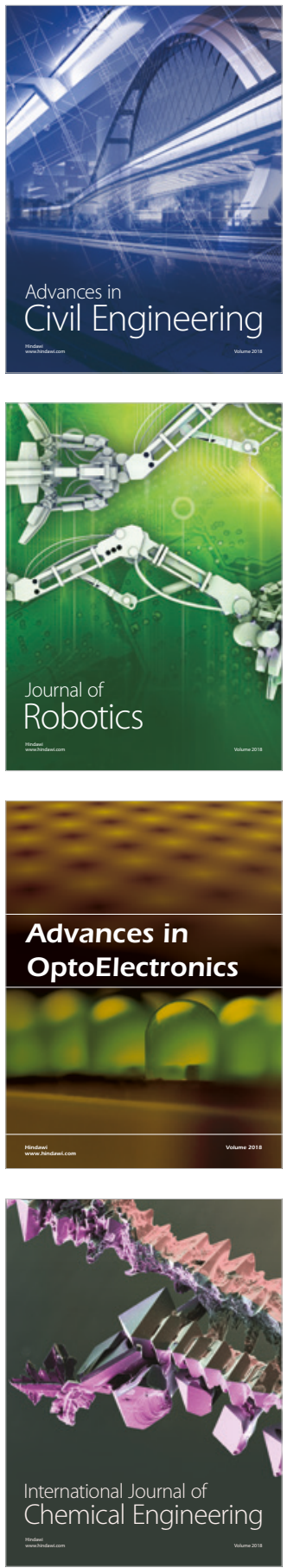

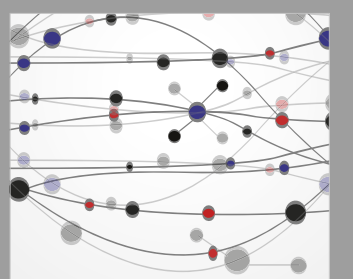

\section{Rotating \\ Machinery}

The Scientific World Journal

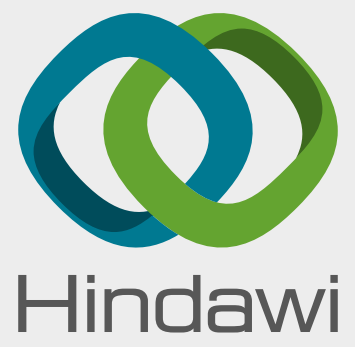

Submit your manuscripts at

www.hindawi.com
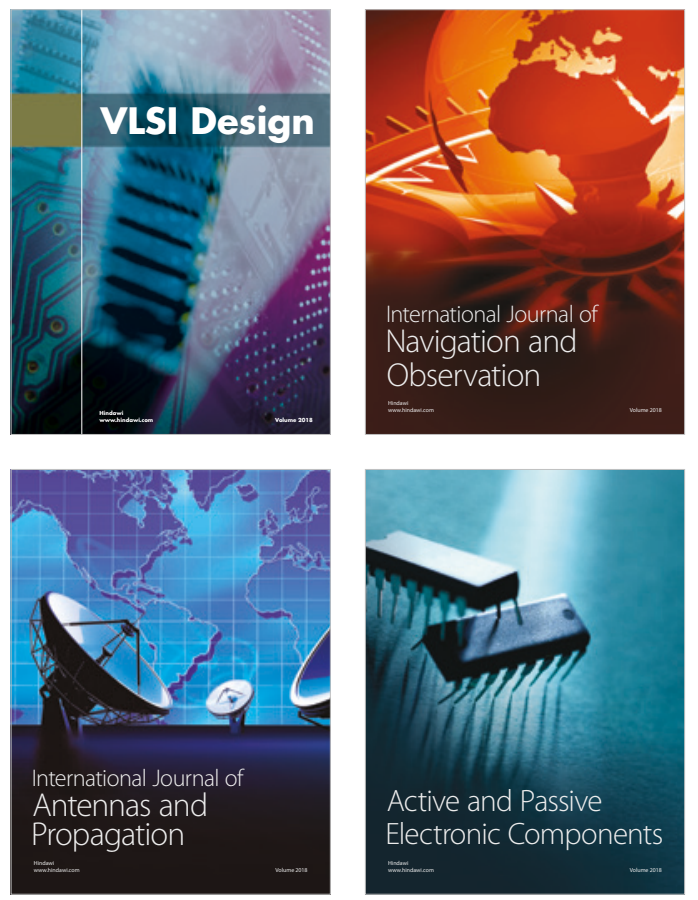
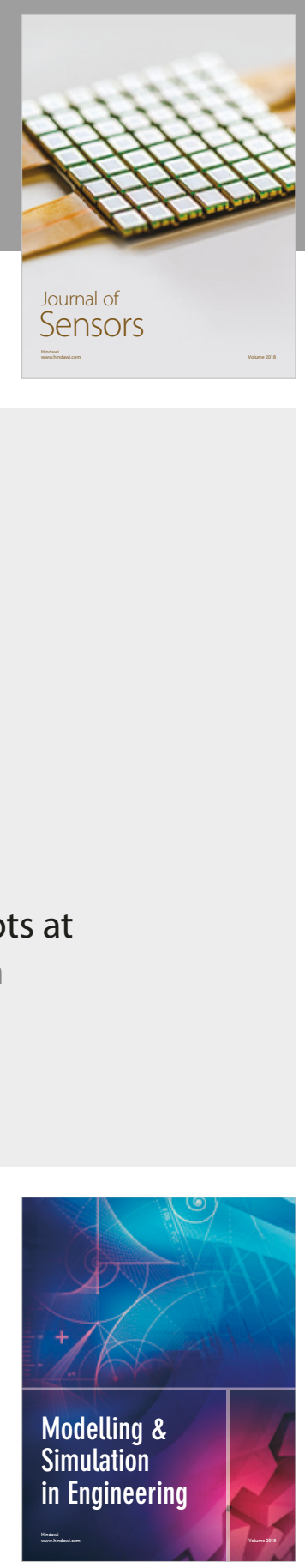

\section{Advances \\ Multimedia}
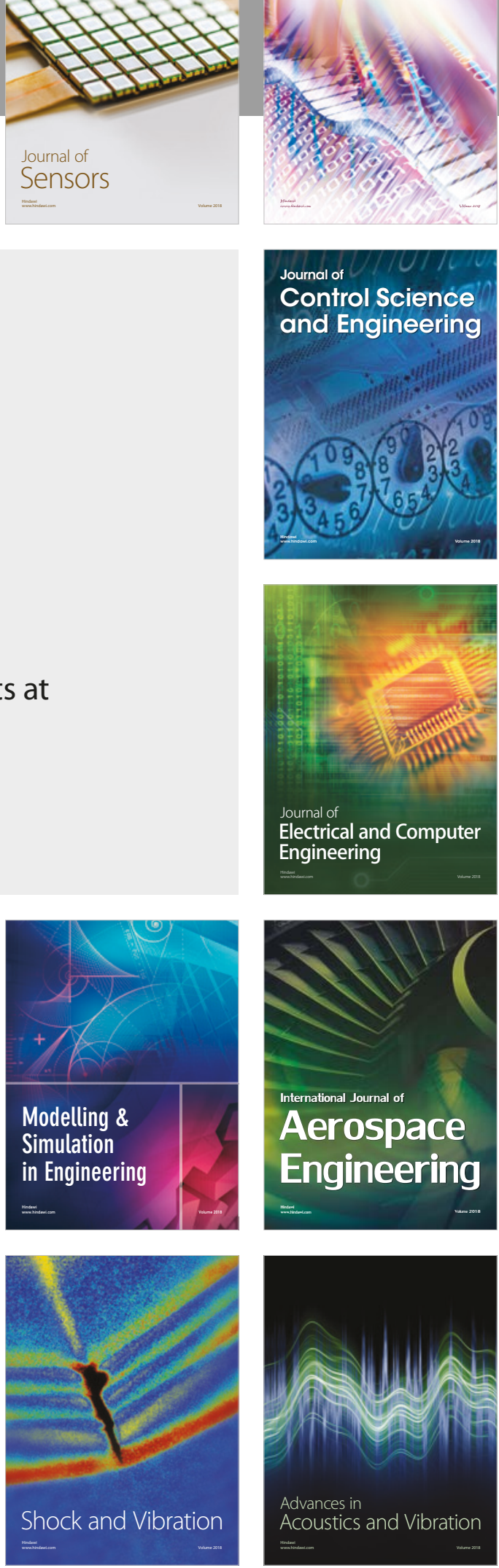